\title{
Manufacturing fit-for-purpose paper packaging containers with controlled biodegradation rate by optimizing addition of natural fillers
}

\author{
Anna Sandak (D) · Jakub Sandak (D) - Izabela Modzelewska
}

Received: 17 April 2018/Accepted: 24 December 2018/Published online: 23 January 2019

(C) The Author(s) 2019

\begin{abstract}
Natural fillers were utilized for manufacturing horticultural packaging products. Five types of pots produced from waste paper with wheat and rye bran additions were compared with commercially available containers. The aim was to examine the influence of soil type on the degradation rate and kinetics. Pots were degraded in three soil types: agriculture, forest and sandy soils and were monitored after 2, 4 and 8 weeks. NIR spectroscopy was used for non-destructive evaluation of the chemical composition of the investigated papers in addition to typically
\end{abstract}

A. Sandak · J. Sandak

CNR-IVALSA Trees and Timber Institute, via Biasi 75,

38010 San Michele all Adige, Italy

\section{A. Sandak · J. Sandak $(\bowtie)$}

InnoRenew CoE Renewable Materials and Healthy

Environments Research and Innovation Centre of

Excellence, Livade 6, 6310 Izola, Slovenia

e-mail: jakub.sandak@innorenew.eu

A. Sandak · J. Sandak

University of Primorska, Titov trg 4, 6000 Koper,

Slovenia

I. Modzelewska

Institute of Chemical Wood Technology, Poznan

University of Life Sciences, ul. Wojska Polskiego 28,

60-637 Poznan, Poland

I. Modzelewska

Printing House "Ekorol" Limited Liability Company, ul.

Ustronna 7, 62-006 Janikowo, Poland used standard methods. All tested configurations of papers might be used for manufacturing of plantable bio-containers that will slowly disintegrate during their use. The addition of cereal bran improves mechanical properties of the paper and extends the lifespan of pots. The rate and extent of decomposition depends mainly on the degradation time and type of soil. Paper pots in all tested configurations degraded most quickly in agricultural and forest soils, each stimulating growth of microorganisms responsible for the decomposition of paper. The obtained results allow selection of products with optimal composition for specific applications and to design the packaging containers degradation time in various in-field scenarios. The manufacturing approach proposed increases the positive footprint of packaging products by designing "eco-effective" solutions according to the Cradle to Cradle design framework. 


\section{Graphical abstract}

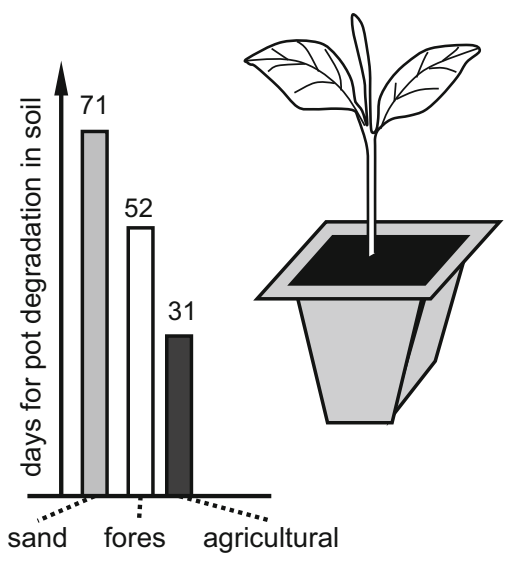

Keywords Waste paper - Paper pots - Cereal bran . Degradation rate $\cdot$ Soil $\cdot$ FT-NIR

\section{Introduction}

Over 67 million tons of packaging wastes are generated annually in the EU, containing up to $30 \%$ of slowly degrading plastics. The Packaging and Packaging Waste Directive, which standardizes the production of packaging materials, waste management and the use of recycling, composting, and energy recovery by incineration regulates the bio-based packing sector (European Parliament and Council Directive 1994). There are clear targets regarding waste reduction in the EU. Seventy-five percent of packaging waste should be recycled by 2030 (Niero and Hauschild 2017). Re-utilization of waste paper is therefore important for reducing waste generation but also for saving wood resources (Kose et al. 2016). According to Chartered Institution of Waste Management, the reduction of waste quantity might save 72 billion $€$ per year and create over 400,000 new jobs in Europe (Cheshire 2016).

The increased use of bio-based materials is essential in order to reduce the environmental impact of materials, including reuse and ultimately, disposal. It is expected that use of biodegradable materials will contribute to sustainability and reduction in the environmental impact associated with disposal costs (Song et al. 2009). Moreover, increased bio-based material use is in line with Circular Economy (CE) objectives, which aims to maximize value at each point in a product's life by keeping products, components and materials at their highest utility at all times (Stahel 2016).

Currently, landfilling is the dominant method of packaging waste disposal, followed by recycling, incineration, and composting (Valdés et al. 2014). However, it is considered as "leakage" from circular system, meaning that valuable resources are wasted and lost from environmental and economical point of view (Cheshire 2016). The most favorable way for transformation of ligno-cellulosic wastes is by recycling. The feasibility of recycled fibers for the production of high value-added papers to be used for packaging purposes was recently reported by Tarrés et al. (2018). However, fibres recovered from paper wastes after re-pulping process have reduced mechanical properties. According to Wistara and Young (1999) tensile strength, bursting strength, and apparent density of the pulps decreases when recycling paper. After a maximum of 6-7 recycling cycles, fibres become too short for further processing. Consequently, additives (new fibres or fillers) are necessary to enrich recycled pulp and to minimize depreciation of its quality (Villanueva and Wenzel 2007). In some circumstances increased use of fillers leads to decrease paper strength (Balea et al. 2018). Moreover, physical recycling may be impractical in case of packaging materials contaminated with foods or other biological substances (Kale et al. 2007). Composting paper waste is considered as one of the less costly disposal routes, and is an option for recycling (López Alvarez et al. 2009). In this scenario, biodegradability becomes a desirable feature for several everyday products, including packaging. Although ultimate biodegradability in the natural environment is important, sustainable packaging products are required to biodegrade in a controlled and industrially acceptable way (Scott and Wiles 2001). However, the main factor that affects the formation and manufacturing of bio-based packaging is related to economic aspects.

Biodegradable pots, developed as an alternative for traditional petroleum derived plastic containers are environmentally friendly and frequently used for silvicultural and agricultural purposes. Such containers reduce overall costs, as seedlings with the biodegradable pots can be planted quickly while avoiding root disturbance or any interruption to plant growth. 
The most commonly used disposable pots are made of peat or a mixture of peat with wood fibres. Such pots can be easily embedded into the soil with plants or converted into bio-gas (digested) after removing the plant. On the other hand, such containers are mechanically unstable and possess high permeability to water vapour. Salt deposition on pot walls is frequently observed and causing nutrient content to become unavailable. This may have a negative impact on plant production and therefore horticulturalists are not always confident to use pots made of peat (Treinyte et al. 2014). Moreover, some consumers avoid the use of peat because peat harvesting may be unsustainable and possibly contribute to global climate change (Mitsch et al. 2013). Containers produced from coconut fibres or bird feathers are interesting alternatives, as these are mechanically more resistant and retain moisture well. However, these cannot be embedded in soil with plants and can only be disposed or digested afterward (Treinyte et al. 2014). Recycled plastic geotextiles are other option recently introduced to the market. These are not easily biodegradable or compostable, but will slowly disintegrate when exposed to the soil. A common limitation of these products is their relatively high price, therefore continuous research regarding development of novel packaging products is ongoing.

Natural fibres and agricultural residues are becoming attractive fibre reinforcement solutions for biocomposites (Ochi 2011; Schettini et al. 2013; Nambuthiri et al. 2015; Tesfaye et al. 2017). Substances from plant waste materials (such as: cellulose, hemicellulose, starch, dextrin, and other carbohydrate polymers) are the most convenient solution as they solve two problems simultaneously: they contribute to efficient waste management and avoid or minimize the use of chemical additives as binders (Müller et al. 2007). A solution that fulfils both of these requirements is cereal bran. In typical flour production processes, cereal bran is devoid of nutrients, and is most often separated for disposal, leading to handling, storage and disposal costs. According to Formela et al. (2016) bran are interesting alternative for commercially available cellulosic fillers and could be successfully applied as a low-cost filler in polymer composites. Therefore, bran may be an ideal filler for the extruded paper or pulp containers used extensively in horticulture. It may also serve as an inhibitor controlling the bio-degradation rate in various products (Sandak et al. 2011).

Evaluation of paper products decomposition in laboratory conditions with selected microorganisms was previously reported (Modzelewska et al. 2010; Jaszczur and Modzelewska 2011; Sandak et al. 2015). However, López Alvarez et al. (2009) have emphasized the necessity to establish biodegradation curves for different packaging products in landfill and/or composting end-of-life scenarios. Such experiments conducted in different soil types and climates are essential before adopting containers made with alternative materials. It is important to note that the same physical characteristics that promote degradation during composting could also contribute to premature degradation during production and transportation. Depending on their capacity to degrade at their endof-life, alternative containers are usually classified as plantable, compostable or recyclable (Nambuthiri et al. 2015).

Various types of soil have different influence on degradation rates mainly due to variability in waterholding capacity (Rahman and Chattopadhyay 2007), available nitrogen, $\mathrm{pH}$, presence of microorganisms and organic matter content (Nambuthiri et al. 2015). In soil with neutral or slightly acid $\mathrm{pH}$ (6.0-7.0), favourable microorganisms and minerals necessary for plant roots are present (Yeomans 1954). Such beneficial bacteria are not present in more acidic soils, leading to uncontrolled mould fungi growth. Moreover, most of minerals are insoluble in soils possessing low $\mathrm{pH}$. Sandy soil is airy and highly permeable. It has rather low water storage capacity, is fast drying and easily loses nutrients due to leaching. In practical applications, it can be improved by adding organic matter or fertilizers. Soil present in coniferous forests contain litter compost composed primarily of pine or spruce needles, ericaceous understorey plant species and mosses (Hilli et al. 2010). The compost is highly acidic but has good leavening properties and can be used as an optimal peat substitute providing favourable conditions for plant growth (Drozd et al. 2002).

Recycled paper containers have been proven to have the comparable wet and dry vertical and lateral strength, similar to those of plastic containers, and showed no algal or fungal growth on the container wall (Nambuthiri et al. 2015). However, additives and fillers might influence the performance of packaging products. 
The goal of this work is to increase the positive footprint of packaging products by designing "ecoeffective" solutions according to the Cradle to Cradle design framework. Reutilization of two kinds of materials (waste paper and cereal bran) is proposed here in order to close the loop at the end of product life cycle. The aim was to design, manufacture and examine the degradation intensity of waste papers containing cereal bran with a special focus on the effect of the soil type. Both, paper sheets and paper pots were evaluated. It is expected that by understanding the degradation rate of the investigated products it will be possible to optimize paper pots manufacturing to assure sufficient mechanical resistance and the desired rate of degradation.

\section{Materials and methods}

\section{Materials}

Two forms of paper products were examined in this study including flat sheets of paper and paper pots. Five configurations were made for both products (Table 1). In case of paper sheets, 24 samples with dimension of $15 \times 95 \mathrm{~mm}$, were cut from each configuration of paper. Fifty pots were manufactured from individual paper type.

\section{Paper sheets}

Paper sheets were produced in the laboratory at University of Life Sciences in Poznan on the RapidKöthen apparatus from recycled pulp type D (cardboard, paper, grey bags, corrugated board), weighing $100 \pm 5 \mathrm{~g} \mathrm{~m}^{-2}$. The pulp was milled on the laboratory mill PFI (till $28 \pm 2^{\circ} \mathrm{SR}$ value). The wetness was measured with a Schopper-Riegler device. The pulp

Table 1 Summary of investigated samples composition

\begin{tabular}{lll}
\hline Sample code & \multicolumn{2}{l}{ Mass content of additives $(\%)$} \\
\cline { 2 - 3 } & Wheat bran & Rye bran \\
\hline WP & 0 & 0 \\
WP3W & 3 & 0 \\
WP5W & 5 & 0 \\
WP3R & 0 & 3 \\
WP5R & 0 & 5 \\
\hline
\end{tabular}

was defibred using a defibrator and formed into sheets of paper with a Rapid-Köthen device. Manufactured papers were made of pulp without and with $3 \%$ or $5 \%$ addition of wheat and rye bran. Both additives were by-product of the flour production and were provided by Gdańskie Młyny i Spichlerze Dr Cordesmeyer Sp. z o.o. The fraction size of bran particles was below $0.4 \mathrm{~mm}$. Details for the sample composition and labelling of investigated papers are summarized in Table 1.

\section{Paper pots}

Paper pots were manufactured in the laboratory from the same pulp as reference flat paper sheets and with identical additives configuration (Table 1). The custom machine for forming pots was developed at University of Life Sciences in Poznan (grant number N30900831). The pot was formed directly in the container from water pulp solution with $2.5 \%$ dry mass concentration. $600 \mathrm{~cm}^{3}$ of the pulp solution was used for manufacturing of each pot. The perforated mold was used to deposit a layer of fibres with additives, where water was removed from the cast by a vacuum pump. The formed pots were dried for $12 \mathrm{~h}$ at $50{ }^{\circ} \mathrm{C}$ in a climatic chamber. The final size of the manufactured pot was $6.0 \times 6.0 \times 5.5 \mathrm{~cm} \quad$ (width $\times$ length $\times$ height, respectively). Degradation and characterization were performed on commercially available products (pots manufactured with the addition of peat) in order to compare their overall performance with laboratory produced pots. Figure 1 presents images of pots manufactured in the laboratory and alternative commercially available products.

\section{Methods}

\section{Degradation in soil}

The substrate used in this experiment was a natural soil sample collected close to Poznan (Poland). The soil was sieved to less than 2-mm particle size before degradation tests, and obvious plant material, stones, or other inert materials were removed. The degradation process was conducted in conditioned laboratory in $20{ }^{\circ} \mathrm{C}$ and $65 \%$ RH. Three different types of soil (sandy, forest and agricultural) were selected as degradation environments for the investigated paper products. The $\mathrm{pH}$ of sandy soil was $\sim 7.5$ to 8.0. 


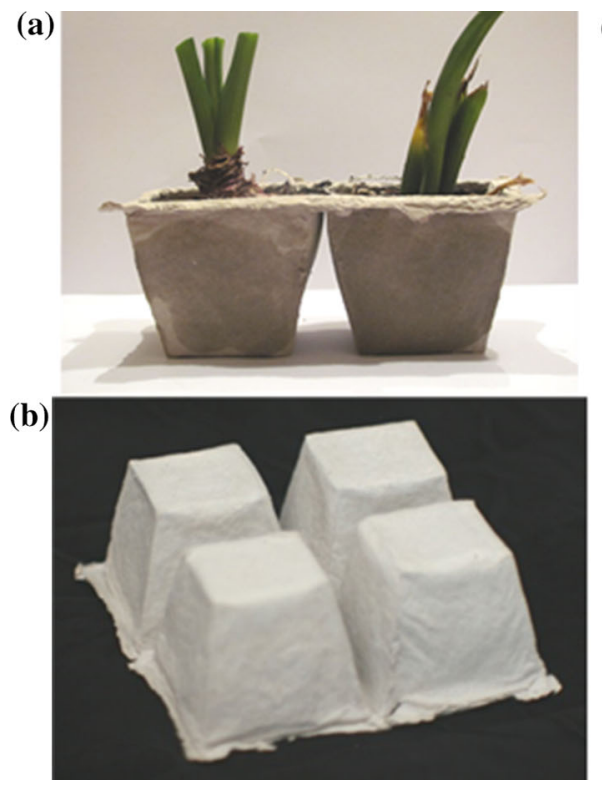

(c)
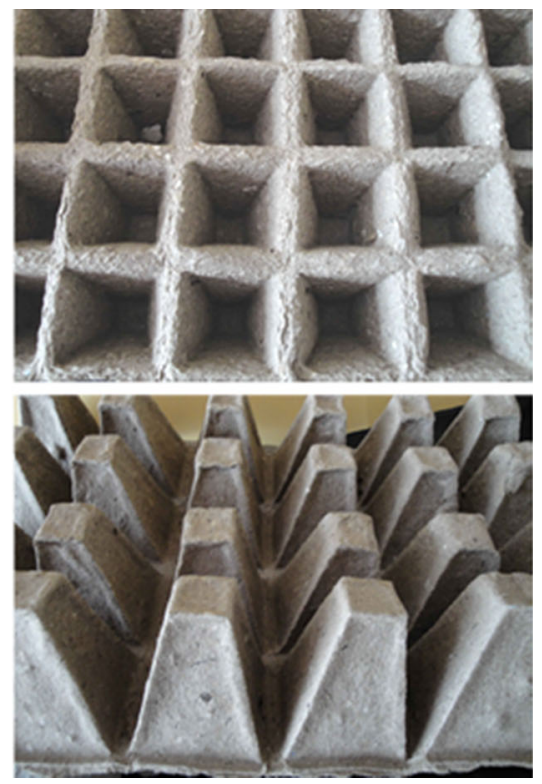

Fig. 1 Plants growing in the bio-degradable paper pots (a), laboratory manufactured prototype pots made of waste pulp with addition of cereal bran (b), commercially available pots made of pulp with addition of peat (c)

Coniferous forest soil is usually enriched with cones and needles, but is rather poor in nutrients. It was the most acid soil studied and had $\mathrm{pH}$ of $\sim 3.5$ to 4.0. Agricultural soil, which consisted of highly decomposed matter deeply mixed with mineral soil had $\mathrm{pH}$ of $\sim 5.0$ and carbon to nitrogen ratio of $\sim 10$. The laboratory experiment was conducted in plastic boxes containing soils. Experimental samples (paper sheets) were fully covered by the soil. Paper pots were placed in the containers to the depth corresponding to $\sim 3 / 4$ of the pot height. All the samples were exposed to the soil for 2 months and the degradation progress was monitored at the 2nd, 4th and 8th week of the experiment. The moisture of the soil during the whole campaign was kept constant in the range of around 55\%. The water capacity of the soil and the ambient temperature was continuously monitored during the tests in order to provide amount of water required to achieve an adequate level of humidity. Containers with samples after installation were kept in climatic chamber $\left(20^{\circ} \mathrm{C}\right.$, $60 \% \mathrm{RH})$. Once a month small amount of water was added to the constant weight of the containers.

\section{Evaluation of paper properties}

The following tests were performed before degradation in soil (according to corresponding standards) in order to characterize the produced paper sheets:
- Breaking length (PN-ISO 1924-1 1998) on the Schopper apparatus.

- Extensibility (PN-EN ISO 1924-2 2009) on the Schopper apparatus.

- Tearing resistance (PN-EN ISO 1974:2012P 2012) on the Elmendorf apparatus.

- Burst test (PN-EN ISO 2758 2005) on the Mullen's apparatus.

- Air permeability according to Gurley (PN-ISO 11004 1995) on the Gurley apparatus.

- Rate of absorbency according to Cobb (PN-EN 20535 1996) on the Cobb apparatus.

In addition, crushing strength was tested on paper pots on the Zwick/Roell Z005 (Zwick Roell AG, Ulm, Germany) mechanical testing machine in compression mode according to TAPPI T804 standard (2006). All the samples were conditioned to $7 \pm 1 \%$ moisture content before characterization. It was impossible to perform all tests on some samples following degradation due to excessive disintegration.

\section{Polymerization degree}

The degree of cellulose polymerization (PD) for paper products was determined on samples before and after soil degradation. During the test, the intrinsic viscosity 
was determined in cupri-ethylenediamine solution (CED) according to ISO 5351-1 (1981).

\section{Chemical analysis}

The concentration of cellulose was determined according to the Seifert procedure by using acetylacetone-dioxane-hydrochloric acid (Browning 1967). The quantities of other wood components were determined according to the following standards:

- Hot water extractives (T207 cm-08 TAPPI 2008).

- $1 \% \mathrm{NaOH}$ extractives (T212 om-07 TAPPI 2007).

The solubility in $1 \% \mathrm{H}_{2} \mathrm{SO}_{4}$ was performed following the same procedure as in $1 \% \mathrm{NaOH}$ (T212 om-07 TAPPI 2007). All the chemical analyses were performed before and after degradation and were repeated three times and the maximum standard deviation of results was considered as the indicator of the measurement error.

\section{Statistical data analysis}

A factorial one-way ANOVA was conducted to compare mean values of chemical components concentration and paper properties at significance level $p<0.05$. In addition, Tukey contrasts simultaneous test for general linear hypothesis with multiple comparison of means was performed post hoc to identify groups of statistically similar samples. The analysis were performed in R software (www.r-project.org) by using multcomp module.

\section{Electron microscopy}

A scanning electron microscope (SEM; S-3400 N, Hitachi High-Tech, Tokyo, Japan) in high vacuum mode with a secondary electron detector was used for imaging samples. It was necessary to coat samples with a thin layer of gold in order to obtain quality SEM images.

\section{FT-NIR measurement}

NIR measurements were made using a Vector $22-\mathrm{N}$ spectrophotometer (Bruker Optics GmbH, Ettlingen, Germany). The measured spectral range was between 4000 and $12,000 \mathrm{~cm}^{-1}(2500 \mathrm{~nm}$ and $833 \mathrm{~nm})$ with a resolution of $8 \mathrm{~cm}^{-1}$. The spectral wavenumber interval was $3.85 \mathrm{~cm}^{-1}$ with zero-filling $=2$. An average of 32 consecutive measurements (internal scans) was acquired for each spectrum. The degradation stage of all papers was determined on three representative paper strips and measured on three spots, before and after 4 and 8 weeks of degradation in each soil. The resulting spectra (9 spectra) were averaged and stored in a data base for further analysis. All measurements were performed in an air-conditioned room $\left(20^{\circ} \mathrm{C}\right.$ and $\left.65 \% \mathrm{RH}\right)$ in order to minimize the effects of the temperature and moisture variations.

\section{Spectral data analysis}

The interpretation of spectra based on Schwanninger et al. (2011) and corresponding band assignments are summarized in Table 2. A narrow range, between 4000 and $6000 \mathrm{~cm}^{-1}$, was selected for spectra interpretation. Computation of the second derivative [21point smoothing, Savitzki and Golay algorithm (1964)] was applied for spectra pre-processing. Spectra were also pre-processed with extended multiplicative scatter correction (EMSC) algorithm for investigation of the degradation rate. Principal component analysis (PCA) was used for data analysis. The commercially available OPUS 7.0 (Bruker Optics
Table 2 Interpretation of the FT-NIR molecular vibrations (Schwanninger et al. 2011)

\begin{tabular}{llll}
\hline $\mathrm{nr}$ & Band assignment & Chemical component & Wavenumber $\left(\mathrm{cm}^{-1}\right)$ \\
\hline 1 & C-H def. & Holocellulose & 4198 \\
2 & C-H def. + C-H str. & Cellulose & 4280 \\
3 & C-H 2 def. + C-H 2 str. & Cellulose & 4404 \\
4 & C-H def. + O-H str. & Cellulose & 4620 \\
5 & C-H def. + O-H str. & Cellulose & 4890 \\
6 & O-H def. + O-H str. & Water & 5219 \\
7 & C-H def. + O-H str. & Semi-crystalline/crystalline cellulose & 5464 \\
\hline
\end{tabular}


$\mathrm{GmBH})$ and Unscrambler ${ }^{\circledR} \mathrm{X}$ (CAMO Software AS) software packages were used for spectra post-processing and data evaluation.

\section{Results and discussion}

The overview of material flow representing manufacturing of design-for-purpose packaging products is presented in Fig. 2. The transition from open loop to closed loop systems is important in order to assure sustainable use of resources and the economic viability of modern bio-based industries. Production of packaging containers proposed here allows valorisation and utilization of waste generated during diverse industrial processes. This approach is in line with the industrial symbiosis concept, where studies regarding flow of materials between industries leads to creation of opportunities to use "waste" from one industry as a raw material for another (Cheshire 2016). In this case fit-for-purpose paper packaging containers are manufactured by combining resources generated by pulp and paper with milling industries. Increasing the recycling and reuse rates of virgin wood fibres leads to increased availability of this resource for other use. However, any recycling round requires a certain amount of virgin paper input, usually from $20 \%$ to 95\% (Villanueva and Wenzel 2007). Incorporation of cereal bran into packaging products allows minimizing virgin wood fibre inputs while maintaining (or improving) the required properties. The set of expected product characteristics can be optimized by adjusting proportion of recycled fibres, virgin fibres and bran (Fig. 2). Moreover, it solves a costly disposal

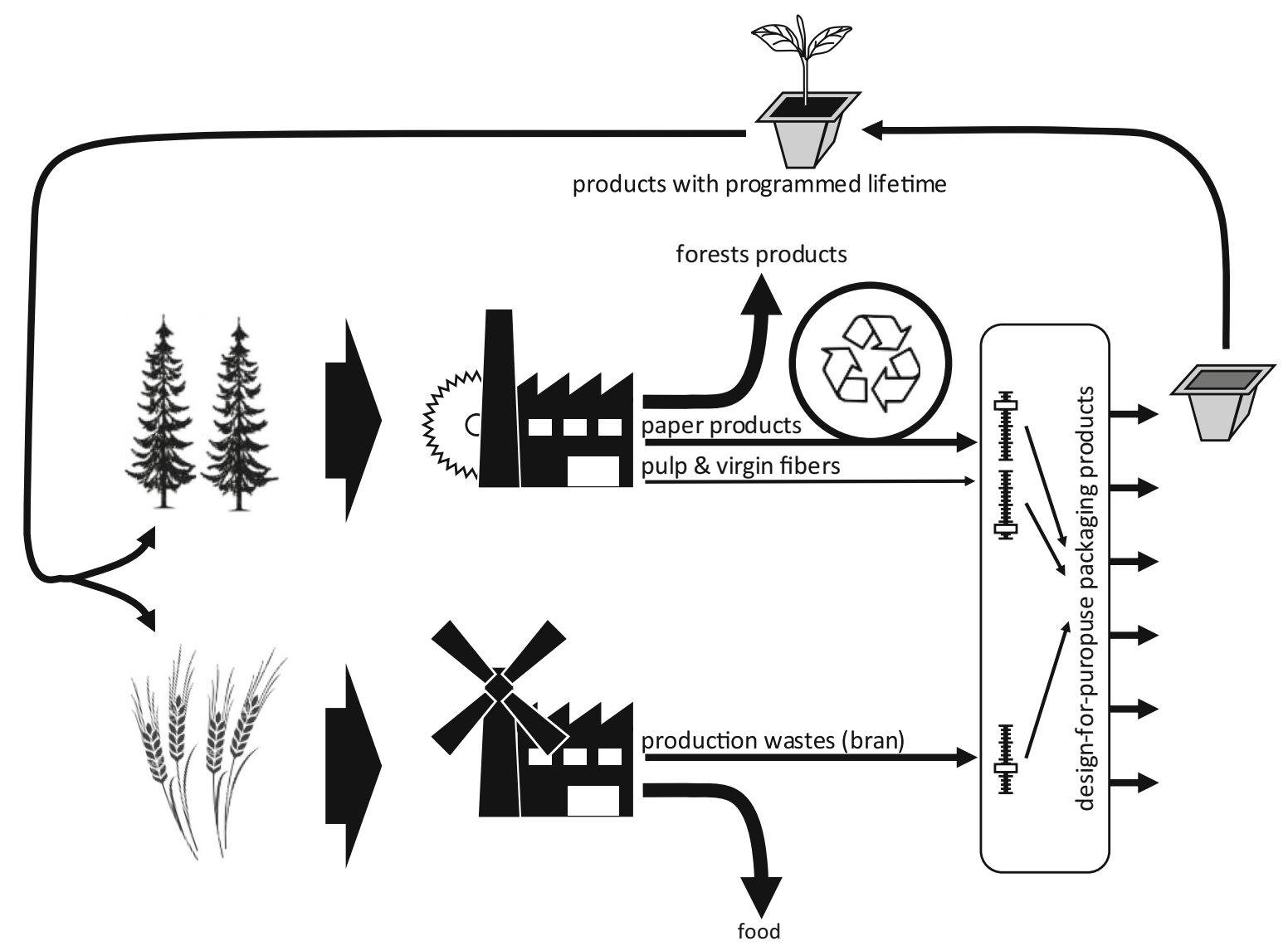

NATURAL RESOURCES

Fig. 2 Scheme of materials flow for manufacturing materials of fit-for-purpose packaging containers 
problem from industrial mills by providing a solution for cereal processing by-products use. Finally, control of the biodegradability rate of manufactured products allows predicting their use phase performance and duration of deterioration.

Effect of the bran additives on the properties of investigated paper products before degradation

The effect of additives on the chemical composition of manufactured paper products is summarized in Table 3. The effect was minor, but for all analysed components the differences between means were statistically significant (ANOVA, $p<0.05$ ). The most noticeable differences are in cellulose content (88.6-91.2\%). Cellulose content in control samples was highest and with increased amount of bran (both types) diminished. It was a direct effect of dilution, as the amount of cellulose is low in bran when compare to the pulp and paper. The cellulose content in bran as reported in literature ranges between 5 and 13\% (Kamal-Eldin et al. 2009; Chalamacharla et al. 2018). In fact, such a high variation in composition within both wheat and rye brans is influenced by the cereal species, provenance, batch and milling techniques applied for flour production. The chemical composition of brans used in this study was researched by Modzelewska and Adamska (2006) and is summarized in Table 4.

The differences in extractives content augmented with the bran share increase.

It is an additional dilution effect of mixing components present in waste paper and bran. The bran itself contains several solvable substances that are contributing to the overall content of extractives. These, beside of cellulose include ash, dietary fibre, proteins, starch and diverse phytochemicals, among the others (Onipe et al. 2015). The relatively high amount of starch in cereal bran (estimated to be 15.8-18.9\% of the dry mass) simplifies the coupling of cellulose fibres and paper forming as well as aids in filling micro-pores. However, as previously reported by the authors, the presence of starch in paper products may advance the degradation rate as it is a favourable breeding ground for bacteria and microfungi (Sandak et al. 2011).

NIR analysis of investigated papers with addition of the rye and wheat brans did not reveal any noteworthy differences between spectra due to presence of bran fillers (Sandak et al. 2011). Only slight variations were noticed for $\mathrm{CH}, \mathrm{CH}_{2}$ and $\mathrm{OH}$ functional groups assigned to cellulose and holocellulose.

Table 3 Chemical composition of papers (\% of dry mass) estimated before and after degradation in agricultural soil

\begin{tabular}{|c|c|c|c|c|c|c|c|c|c|c|}
\hline \multirow[t]{3}{*}{ Paper type } & \multicolumn{5}{|c|}{ Before degradation } & \multicolumn{5}{|c|}{ After degradation in agricultural soil } \\
\hline & \multirow[t]{2}{*}{ Cellulose* } & \multicolumn{3}{|c|}{ Extractives } & \multirow[t]{2}{*}{ PD } & \multirow[t]{2}{*}{ Cellulose* } & \multicolumn{3}{|c|}{ Extractives } & \multirow[t]{2}{*}{ PD } \\
\hline & & $\mathrm{H}_{2} \mathrm{O} *$ & $1 \% \mathrm{NaOH}^{*}$ & $1 \% \mathrm{H}_{2} \mathrm{SO}_{4} *$ & & & $\mathrm{H}_{2} \mathrm{O} *$ & $1 \% \mathrm{NaOH}^{*}$ & $1 \% \mathrm{H}_{2} \mathrm{SO}_{4} *$ & \\
\hline SD & 0.1 & 0.1 & 0.1 & 0.1 & - & 0.1 & 0.1 & 0.1 & 0.1 & - \\
\hline WP & $91.2^{\mathrm{d}}$ & $2.4^{\mathrm{a}}$ & $15.1^{\mathrm{a}}$ & $10.2^{\mathrm{a}}$ & 1102 & $83.5^{\mathrm{d}}$ & $2.8^{\mathrm{a}}$ & $16.0^{\mathrm{b}}$ & $13.8^{\mathrm{b}}$ & 949 \\
\hline WP3W & $90.0^{\mathrm{c}}$ & $2.9^{\mathrm{cd}}$ & $15.5^{\mathrm{b}}$ & $10.5^{\mathrm{b}}$ & 1100 & $82.0^{\mathrm{c}}$ & $3.3^{b c}$ & $15.8^{\mathrm{ab}}$ & $13.6^{\mathrm{ab}}$ & 954 \\
\hline WP5W & $89.6^{\mathrm{b}}$ & $3.1^{\mathrm{d}}$ & $16.7^{\mathrm{d}}$ & $12.7^{\mathrm{d}}$ & 1097 & $76.9^{\mathrm{b}}$ & $3.5^{\mathrm{c}}$ & $15.7^{\mathrm{a}}$ & $13.5^{\mathrm{a}}$ & 950 \\
\hline WP3R & $90.0^{\mathrm{c}}$ & $2.5^{\mathrm{ab}}$ & $16.5^{\mathrm{cd}}$ & $11.5^{\mathrm{c}}$ & 1101 & $77.1^{\mathrm{b}}$ & $3.2^{\mathrm{b}}$ & $15.9^{\mathrm{ab}}$ & $13.4^{\mathrm{a}}$ & 955 \\
\hline WP5R & $88.6^{\mathrm{a}}$ & $2.7^{\mathrm{bc}}$ & $16.3^{\mathrm{c}}$ & $12.5^{\mathrm{d}}$ & 1097 & $76.2^{\mathrm{a}}$ & $3.4^{\mathrm{bc}}$ & $15.7^{\mathrm{a}}$ & $13.5^{\mathrm{a}}$ & 954 \\
\hline
\end{tabular}

*Differences significant at $p<0.05$, letters in superscript correspond to the statistically similar groups determined with Tukey post hoc test

$\mathrm{SD}$, maximum standard deviation of results; $\mathrm{PD}$, polymerization degree

Table 4 Chemical composition (\% of dry mass) of rye and wheat bran

\begin{tabular}{llllllll}
\hline Bran type & Cellulose & Holocellulose & Starch & Lignin & Hot water extractives & Cold water extractives & Ash \\
\hline Wheat & 12.7 & 43.1 & 18.9 & 10.4 & 25.8 & 25.1 & 3.7 \\
Rye & 10.5 & 20.8 & 15.8 & 9.3 & 44.5 & 26.6 & 3.5 \\
\hline
\end{tabular}


Table 5 Selected properties of papers with added bran

\begin{tabular}{lllllll}
\hline $\begin{array}{l}\text { Paper } \\
\text { type }\end{array}$ & $\begin{array}{l}\text { Breaking length* } \\
(\mathrm{km})\end{array}$ & $\begin{array}{l}\text { Extensibility* } \\
(\%)\end{array}$ & $\begin{array}{l}\text { Tearing resistance* } \\
(\mathrm{mN})\end{array}$ & $\begin{array}{l}\text { Burst test* } \\
(\mathrm{kPa})\end{array}$ & $\begin{array}{l}\text { Air permeability* } \\
(\mathrm{s})\end{array}$ & $\begin{array}{l}\text { Absorbency* } \\
\left(\mathrm{g} / \mathrm{m}^{2}\right)\end{array}$ \\
\hline WP & $2.9^{\mathrm{a}}$ & $0.97^{\mathrm{b}}$ & $980^{\mathrm{b}}$ & $567^{\mathrm{a}}$ & $4.5^{\mathrm{a}}$ & $166^{\mathrm{b}}$ \\
WP3W & $3.4^{\mathrm{b}}$ & $0.87^{\mathrm{a}}$ & $879^{\mathrm{a}}$ & $678^{\mathrm{b}}$ & $4.8^{\mathrm{ab}}$ & $184^{\mathrm{c}}$ \\
WP5W & $3.4^{\mathrm{b}}$ & $0.93^{\mathrm{b}}$ & $880^{\mathrm{a}}$ & $689^{\mathrm{b}}$ & $5.0^{\mathrm{ab}}$ & $190^{\mathrm{c}}$ \\
WP3R & $3.8^{\mathrm{c}}$ & $0.97^{\mathrm{b}}$ & $960^{\mathrm{b}}$ & $683^{\mathrm{b}}$ & $6.1^{\mathrm{c}}$ & $123^{\mathrm{a}}$ \\
WP5R & $3.9^{\mathrm{c}}$ & $1.05^{\mathrm{c}}$ & $870^{\mathrm{a}}$ & $689^{\mathrm{b}}$ & $5.1^{\mathrm{b}}$ & $182^{\mathrm{c}}$ \\
\hline
\end{tabular}

*Differences significant at $p<0.05$, letters in superscript correspond to the statistically similar groups determined with Tukey post hoc test

The influence of bran additives on selected paper properties is summarized in Table 5. The breaking length of papers with bran additives is about $25 \%$ higher than control samples. It can be explained by a positive effect of the filler increasing the number of connections between paper fibres and therefore the degree of bonding (Retulainen and Ebeling 1993). In this case the bran particles take part in the hydrogen bonds promoting consolidation of the paper structure. It was also noticed that the effect of mixing fibres with bran additions was not following the linear rule of mixture (Karlsson 2007). The breaking length increase was not significantly higher in $5 \%$ bran content compare to $3 \%$. The breaking length was highest for paper products with rye bran.

The addition of bran seems to have rather casual influence on the paper extensibility, even if increased share of bran slightly augmented extensibility value. Conversely, tearing resistance diminished with increase of the bran content. It was expected as tearing is usually inversely correlated with the tensile strength and breaking length (Caufield and Gunderson 1988). The reduction of tearing can be explained by the fact that addition of bran particles affects fibre-fibre bonding promoting pulling up of fibres out the network (Yu 2001).

The burst resistance index, frequently used to determine the quality of paper, does not depend on the kind, but rather on the amount of filler introduced. It is lowest for the paper without additives, and slightly increases with the added bran content. The trend corresponds to that expected as the burst resistance is as well correlated to the tensile strength (Caufield and Gunderson 1988).

Air permeability and absorbance increased in papers with additives. Both properties might be desirable when increased barrier properties against water are required. In the case of waste paper, adding bran leads to early disassembly of the structure of the paper while exposed to degradation; consequently, affecting the air permeability. This peculiarity has a beneficial effect for paper pots, where high air permeability improves the natural ventilation of the root system and stimulates plant growth (Nambuthiri et al. 2015; Akelah 2013).

The results of mechanical tests for the compression strength of paper pots before degradation are presented in Table 6 . The lowest crushing strength was

Table 6 Results of the crushing strength of paper pots $(\mathrm{kPa})$

\begin{tabular}{lllll}
\hline Pot type & Crushing strength* $(\mathrm{kPa})$ & $\mathrm{SD}(\mathrm{kPa})$ & The crushing strength after 3 compression cycles* $(\mathrm{kPa})$ & SD $(\mathrm{kPa})$ \\
\hline WP & $414^{\mathrm{e}}$ & 12 & $388^{\mathrm{d}}$ & 11 \\
WP3W & $359^{\mathrm{d}}$ & 15 & $320^{\mathrm{c}}$ & 6 \\
WP5W & $339^{\mathrm{c}}$ & 5 & $300^{\mathrm{a}}$ & 7 \\
WP3R & $330^{\mathrm{b}}$ & 8 & $299^{\mathrm{a}}$ & 6 \\
WP5R & $357^{\mathrm{d}}$ & 14 & $315^{\mathrm{b}}$ & 6 \\
Commercial pots & $291^{\mathrm{a}}$ & 9 & $0^{* *}$ & - \\
\hline
\end{tabular}

*Differences significant at $p<0.05$, letters in superscript correspond to the statistically similar groups determined with Tukey post hoc test

**Experimental samples were damaged already after first compression cycle 


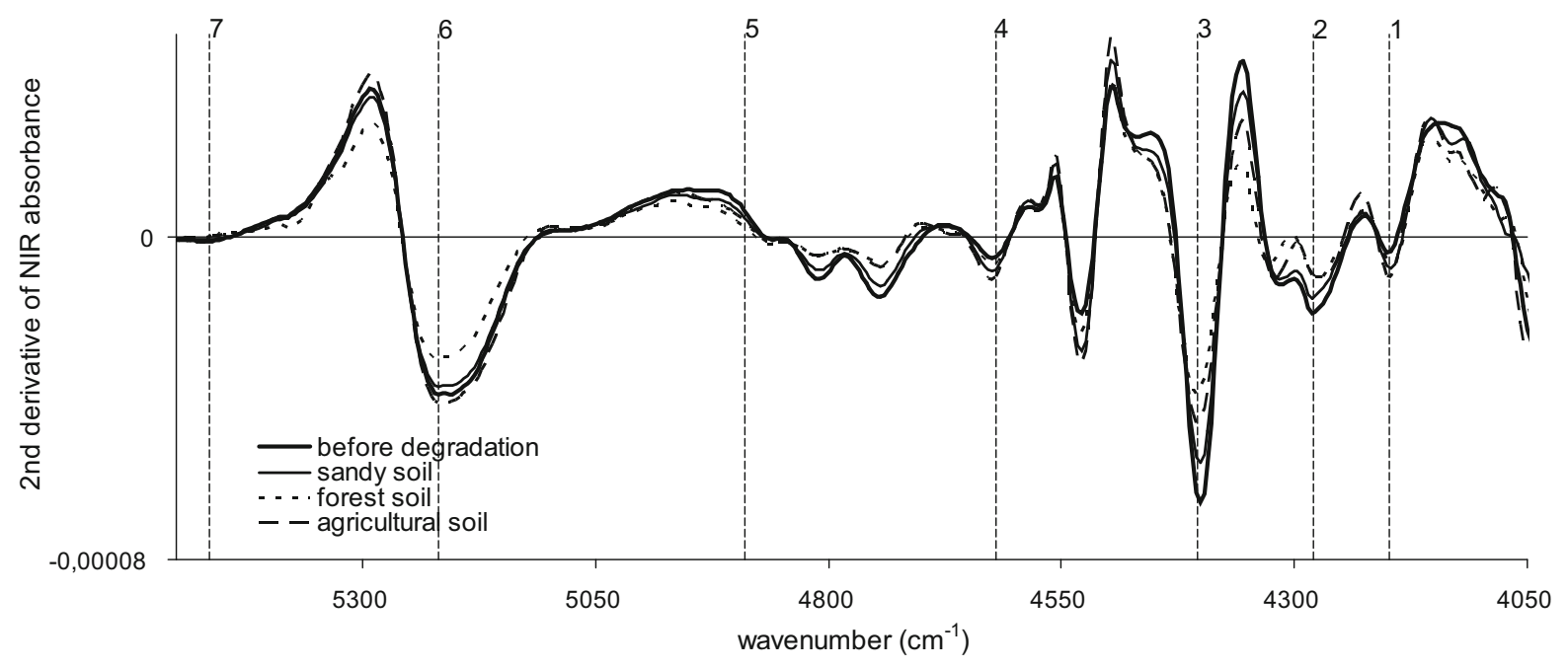

Fig. 3 Effect of soil type on the biodegradation of the recycled paper with addition of 5\% wheat bran for 8 weeks

observed for commercial pots. Pots without additives (WP) possessed the highest mechanical resistance among all laboratory-manufactured products and any bran addition lowered the crushing strength. It was also found that paper pots with added peat were brittle, as did not retain any strength after first compression cycle. Conversely, pots manufactured from waste paper with added bran were elastic, maintaining integrity after several cycles.

Changes to paper due to biodegradation in soil

Degradation processes take place in the natural environment constantly and on a large scale (Pagga 1999). Biodegradation in soil is an important end-oflife option for bio-based materials used in agricultural applications. The rate of degradation can vary significantly, depending not only on the molecular structure of the material, but also on soil characteristics and conditions (temperature, water and oxygen availability which influence microbial activity) (Briassoulis et al. 2014). Biodegradation occurs in two steps. First, the polymers are fragmented into lower molecular mass by means of abiotic reactions (oxidation, photodegradation or hydrolysis) or biotic reactions (degradations by microorganisms). Then the polymer fragments are assimilated and mineralized by microorganisms (Vroman and Tighzert 2009).

The effect of soil type on the biodegradation of investigated papers was analysed by means of NIR spectroscopy. Figure 3 presents an example of degradation progress, where the evolution of the spectra acquired after degrading sample WP5W (waste paper with addition of 5\% wheat bran) in various soils is presented. All peaks mentioned in Table 2, with exception of region $5464 \mathrm{~cm}^{-1}$ (7) were affected by the degradation process. However, the spectra of paper placed in a sandy soil seems to be most similar to the control samples. It demonstrates that the sandy soil containing the lowest organic content and persistent low humidity has the lowest impact on the speed of degradation, as in Mostafa et al. (2010). In contrast, the agricultural and forest soil accelerated the degradation speed.

Analyses of the chemical composition of the papers after degradation in agricultural soil for 8 weeks are summarized in Table 3. Cellulose changed considerably after degradation, including quality and quantity alterations, as observed also by Shogren (1999). The amount of cellulose decreased in all investigated cases, where major changes (over 12\%) were observed for paper with rye bran and with $5 \%$ of wheat bran. Conversely, the cellulose polymerization degree PD drop was slightly higher for papers without any bran additives. The content of extractive components was higher after biodegradation, especially in the case of extraction in $1 \% \mathrm{H}_{2} \mathrm{SO}_{4}$. It can be explained as a result of constitutive polymers degradation due to hydrolysis and biotic factors (Witkowska et al. 1989).

Microscopic analysis allows the assessment of changes in the micro structure of cellulose fibres as results of the degradation. Selected SEM microscopic 

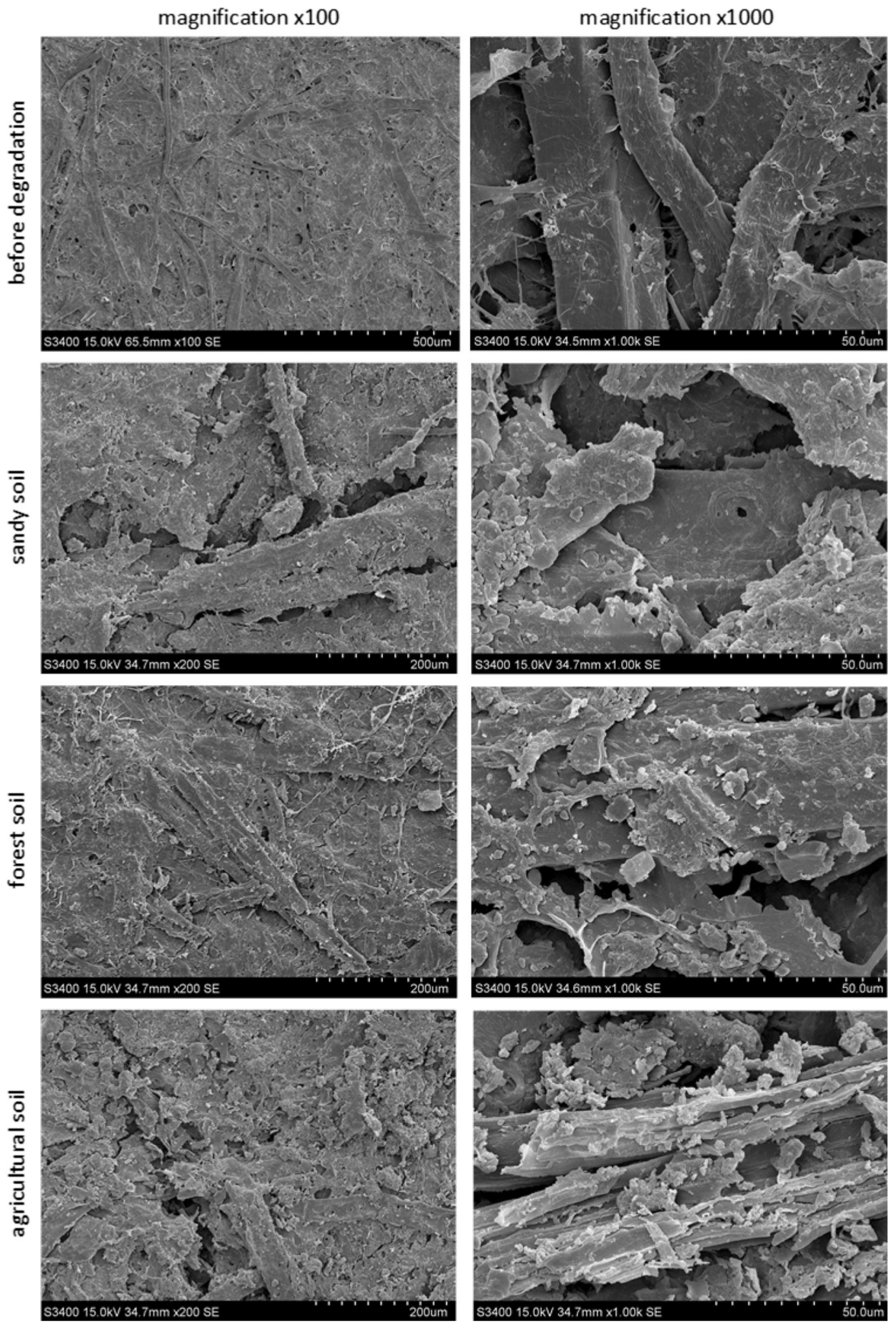

Fig. 4 Microscopic pictures of the paper WP3W surface before and after biodegradation in sandy, forest and agricultural soils 
images of the WP3W paper samples (waste paper with addition of 3\% wheat bran) before and after degradation are shown in Fig. 4. The apparent presence of both bacteria and fungi are noticed on the degraded paper surface. It was particularly evident in the outer layer, where fungal hyphae and spores are clearly visible. Swelling of the cellulose fibres caused by breaking bonds stimulated the microorganism's growth and their further penetration toward paper bulk. It was especially noticeable in samples collected from agricultural soil, where the water reservoir was maintained at high level, and where degradation was more advanced.

The mechanical properties of paper were measured on the experimental samples before and after degradation. Table 7 presents the progression of the breaking length before testing, and after 2, 4, and 8 weeks of soil exposure for all investigated papers. The results obtained from samples before exposure confirm the positive impact of fillers on the mechanical resistance of paper products and corresponds to trends reported by other researchers (Nechita et al. 2010; Gonzalo et al. 2017). None of the samples were suitable for mechanical testing after 8 weeks of exposure due to excessive degradation. The highest degradation kinetics, as related to the breaking length loss, were observed on samples degraded in the agricultural soil. Mechanical properties had dropped significantly already after two weeks of exposure. According to Sridach et al. (2007) 50-80\% of tensile strength is lost during the first week of burial process depending on the type of paper product and its composition. There are several thousands of paper types produced nowadays by the pulp and paper industries. The paper products differs due to composition, formula, additives, binders, fillers, retention agents, among the others. However, the highest impact has a variation within cellulose mass used for paper making that is produced with variety of pulping, bleaching, sizing, strengthening, drying and/or coating processes. The raw resource used in this research was of recycled paper origin. The composition of fibers was therefore highly anisotropic as well as each resource batch may be different than another. In addition, printing residuals with other impurities introduce important discrepancy to the paper products derived. It affects also the degradation processes of papers when exposed to soil, making universal determination of the detailed degradation mechanism rather difficult.

The effect of degradation duration on the NIR spectra of sample WP5W (waste paper with addition of 5\% wheat bran) is shown in Fig. 5. Curves for most spectra bands differ from the control state (not exposed for degradation) after exposure for 4 weeks. Spectra are similar at 4 and 8 weeks exposure. This implies that partial decomposition of the examined paper products in forest soils had occurred by week four.

The chemical decomposition of different papers can be compared with principal components analysis (PCA) derived from NIR spectra. Figure 6 presents a PCA plot for three series of spectra corresponding to samples at different degradation stages of the tested papers in forest soil. Samples before degradation are grouped together in relatively small cluster. The highest dispersion of spectra was observed at 4 weeks' exposure, while tighter clustering was observed again after 8 weeks. The high degree of scatter observed at 4 weeks exposure, together with minor cluster overlapping signifies a high heterogeneity within all tested papers as well as varied degradation kinetics, being dependent on the paper type.
Table 7 Breaking length $(\mathrm{km})$ of investigated paper before and after soil degradation

\begin{tabular}{|c|c|c|c|c|c|c|c|c|c|c|}
\hline \multirow{3}{*}{$\begin{array}{l}\text { Soil type } \\
\text { Degradation time }\end{array}$} & \multirow{3}{*}{$\begin{array}{l}\text { Before } \\
0\end{array}$} & \multicolumn{9}{|l|}{ After } \\
\hline & & \multicolumn{3}{|c|}{ Forest } & \multicolumn{3}{|l|}{ Sand } & \multicolumn{3}{|c|}{ Agricultural } \\
\hline & & 2 & 4 & 8 & 2 & 4 & 8 & 2 & 4 & 8 \\
\hline WP & 2.85 & 1.37 & 0.38 & 0 & 1.59 & 0 & 0 & 1.00 & 0.12 & 0 \\
\hline WP3W & 3.38 & 1.37 & 0.40 & 0 & 1.50 & 0.38 & 0 & 0.60 & 0.45 & 0 \\
\hline WP5W & 3.40 & 1.39 & 0.72 & 0 & 1.56 & 0.64 & 0 & 0.78 & 0.42 & 0 \\
\hline WP3R & 3.81 & 1.42 & 0.62 & 0 & 1.62 & 0.50 & 0 & 0.77 & 0.30 & 0 \\
\hline WP5R & 3.88 & 1.45 & 0.85 & 0 & 1.69 & 0.80 & 0 & 0.83 & 0.62 & 0 \\
\hline
\end{tabular}




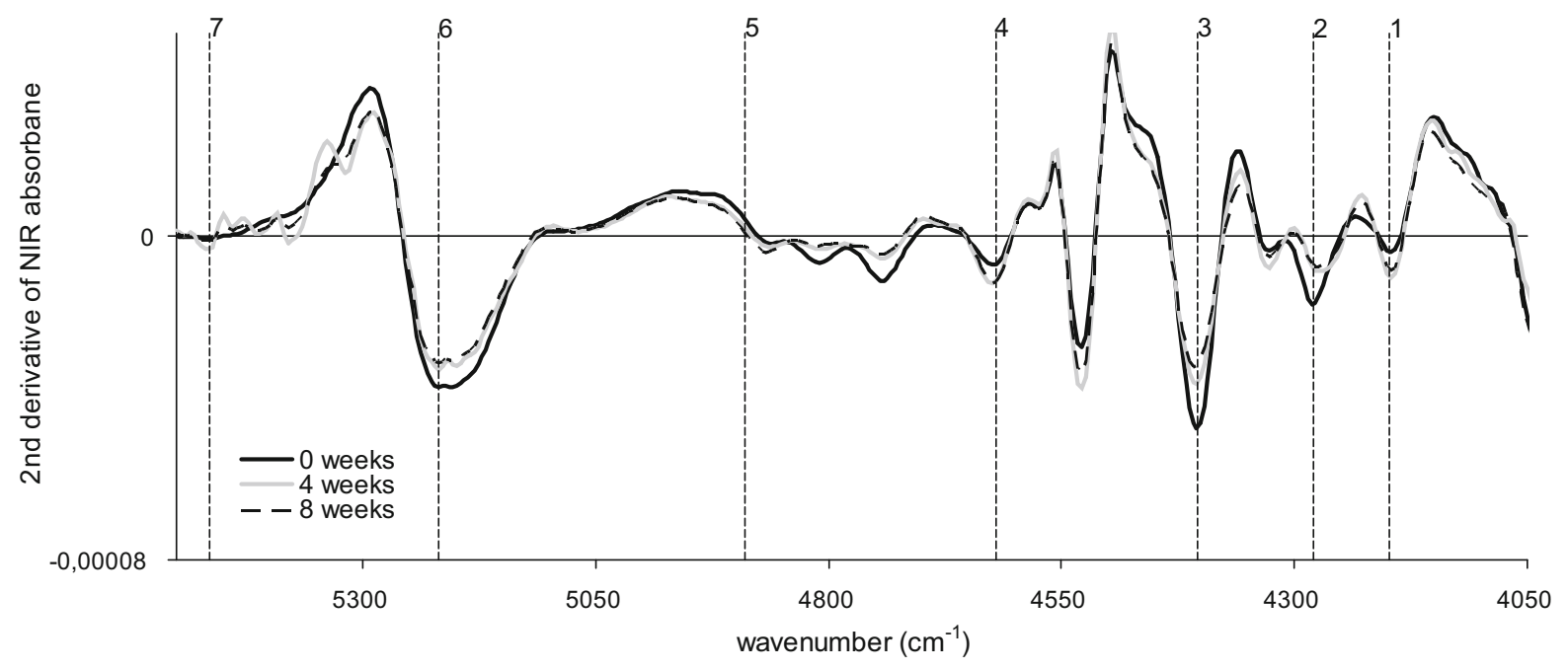

Fig. 5 Effect of time on the biodegradation of the recycled paper with addition of $5 \%$ wheat bran in the forest soil

The vulnerability of the paper to degradation in soil was assessed by comparing the expected time to complete paper degradation. These degradation ratings for both sheets and pots, are summarized in Fig. 7 for all examined samples. Values were determined by visual estimation according to expert persons as the number of days until a terminal state would be reached. Disintegration of the paper sheet or decomposition $>75 \%$ of the paper pot was considered as a terminal state.

The lowest rate of degradation is expected when paper is exposed to sandy soil, where the degradation process is estimated to take between 60 and 70 days (depending on paper composition) (Fig. 7a). A higher degree susceptibility to degradation was observed for samples exposed to the forest soil, regardless of paper type; it was estimated that complete biodegradation occurred in 40-50 days for all paper types in forest soil. Agricultural soil was considered to be the most aggressive because complete paper destruction was expected after only 30 days (compared to approximately 60 days for sandy soil). It corresponds to the previous studies where Tumer et al. (2013) reported that changes related to the decomposition were most intense in organic soil, when compared to sandy soil The presence of fillers reduced life of the paper products, despite products with $5 \%$ bran filler being observed to be more resistant to biodegradation than those with $3 \%$ bran filler.

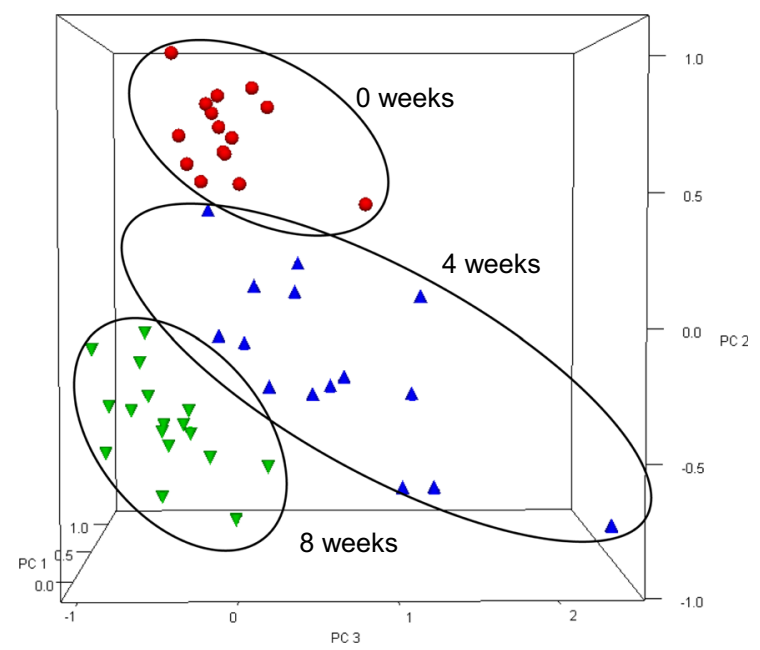

Fig. 6 PCA analysis of NIR spectra of paper before degradation tests and decomposed in forest soil for 4 and 8 weeks. Note spectral range: $11,000-4150 \mathrm{~cm}^{-1}$, pre-processing: 2 nd derivative + vector normalization

The estimated biodegradation rates of pots were similar to those of paper sheets (Fig. 7b). Commercial pots were found to decompose more rapidly than the products manufactured in the laboratory. This was due to the relatively large share of additives that increase water absorption and hasten decomposition. The laboratory-made pots with rye bran filler decomposed slightly faster than other samples. Therefore, it might be possible to adjust the degradation rate of waste paper by adding specific fillers and to deliver products most suitable for specific applications. 
Fig. 7 Visually estimated degradation rates for paper sheets (a) and pots (b), when exposed to different soils

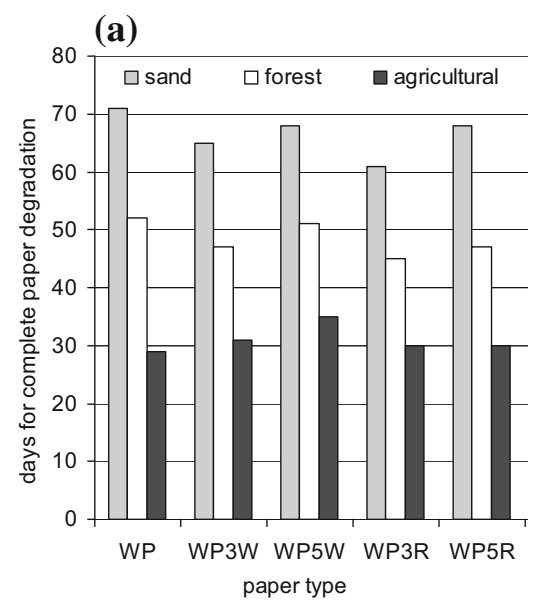

\section{Conclusions}

The cereal bran used in this experiment was characterized by a relatively high starch content. Starch promotes the binding of natural fibres during paper manufacturing and consequently improves the paper strength. Mechanical properties are particularly important in the production and utilization of paper pots manufactured from recycled fibres. The addition of cereal bran improved the mechanical properties of paper products tested in this study; paper pots with bran fillers were less susceptible to mechanical damage, when compare with commercial products. The biodegradation rate of pots changes with the quantity of added bran. Biodegradation in these pots is generally slower than in commercial pots containing peat, but faster than in pots without fillers.

It was concluded that the extent of decomposition does not extensively depend on the type of filling (rye or wheat cereal bran), but rather on the quantity of filler added, exposure time and soil type. Depending on the soil type, water holding capacity and $\mathrm{pH}$, soil may stimulate or inhibit the growth of microorganisms responsible for the decomposition of paper products. Paper samples (both sheets and pots) in all tested configurations degraded most rapidly in agricultural and forest soils, while biodegradation proceeded slowly in the sand soil.

Analysis of NIR spectra revealed that the most advanced degradation occurred in agricultural soil. The organic content accelerated the degradation rate within all investigated papers. In contrast, sandy soil, which is low in organic matter, resulted in the lowest degradation rate and inhibited degradation processes.
All tested paper configurations could be suitable for manufacturing plantable bio-containers that will slowly disintegrate during their lifespan. Their use improves both the sustainability and public perception of the investigated products. However, in addition to environmental and economic aspects, the effect of alternative containers on plant growth and quality should be considered. Therefore, our future work will be related to calculation of environmental impact of manufactured paper packaging products. Proper use of the experimental results may help in selection of products with optimal composition for specific applications, including pots used in horticulture or for forest nurseries. Moreover, by proper fillers selection, packaging products with custom degradation rate best suited to certain crop cycle durations and adopted for specific types of soils may be designed.

Acknowledgments Part of this work was conducted within the framework of the project BIO4ever (RBSI14Y7Y4) funded within the SIR (Scientific Independence of young Researchers) call by MIUR. The authors gratefully acknowledge the European Commission for funding the InnoRenew $\mathrm{CoE}$ project (Grant Agreement \#739574) under the Horizon2020 Widespread-Teaming program and the Republic of Slovenia (Investment funding of the Republic of Slovenia and the European Union of the European Regional Development Fund).

Open Access This article is distributed under the terms of the Creative Commons Attribution 4.0 International License (http:// creativecommons.org/licenses/by/4.0/), which permits unrestricted use, distribution, and reproduction in any medium, provided you give appropriate credit to the original author(s) and the source, provide a link to the Creative Commons license, and indicate if changes were made. 


\section{References}

Akelah A (2013) Functionalized polymeric materials in agriculture and the food industry. Springer, New York

Balea A, Merayo N, Fuente E, Negro C, Delgado-Aguilar M, Mutje P, Blanco A (2018) Cellulose nanofibers from residues to improve linting and mechanical properties of recycled paper. Cellulose 25(2):1339-1351. https://doi. org/10.1007/s10570-017-1618-x

Briassoulis D, Mistriotis A, Mortier N, De Wilde B (2014) Standard testing methods and specifications for biodegradation of bio-based materials in soil-a comparative analysis. In: Proceedings international conference of agricultural engineering, Zurich, Ref: C0668. http://www. geyseco.es/geystiona/adjs/comunicaciones/304/ C06680001.pdf. Accessed 20 Nov 2017

Browning BL (1967) Methods of wood chemistry: interscience, vol I. Wiley, New York

Caufield DF, Gunderson DE (1988) Paper testing and strength characteristics. TAPPI paper preservation symposium, October 19-21, Washington, DC, pp 31-40

Chalamacharla RB, Harsha K, Sheik KB, Viswanatha CK (2018) Wheat bran-composition and nutritional quality: a review. Adv Biotech Microbiol 9(1):555754. https://doi. org/10.19080/AIBM.2018.09.55575

Cheshire D (2016) Building revolutions: applying the circular economy to the built environment. RIBA Publishing, London

Drozd J, Licznar M, Licznar S, Weber J (2002) Gleboznawstwo $\mathrm{z}$ elementami mineralogii i petrografii. UP we Wrocławiu, Wroclaw (in polish)

European Parliament and Council Directive 94/62/EC of 20 December 1994 on packaging and packaging waste. Off J Eur Commun L 365/11

Formela K, Hejna A, Piszczyk Ł, Saeb MR, Colom X (2016) Processing and structure-property relationships of natural rubber/wheat bran biocomposites. Cellulose 23:3157-3175. https://doi.org/10.1007/s10570-016-10200

Gonzalo A, Bimbela F, Sanchez J, Labidi J, Martin F, Arauzo J (2017) Evaluation of different agricultural residues as raw materials for pulp and paper production using a semichemical process. J Clean Prod 156:184-193. https://doi. org/10.1016/j.jclepro.2017.04.036

Hilli S, Starka S, Derome J (2010) Litter decomposition rates in relation to litter stocks in boreal coniferous forests along climatic and soil fertility gradients. Appl Soil Ecol 46:200-208

ISO 5351-1 (1981) Cellulose in dilute solutions; determination of limiting viscosity number; part 1: method in cupriethylene-diamine (CED) solution. International Organization for Standardization Geneva, Switzerland

Jaszczur A, Modzelewska I (2011) Comparative analysis of impact of starch and resin adhesive on the biodegradation process of selected paper products. Ann WULS SGGW For Wood Technol 74:134-138

Kale G, Kijchavengkul T, Auras R, Rubino M, Selke SE, Singh SP (2007) Compostability of bioplastic packaging materials: an overview. Macromol Biosci 7(3):255-277. https:// doi.org/10.1002/mabi.200600168
Kamal-Eldin A, Nygaard Lærke H, Knudsen KAB, Lampi AM, Piironen V, Adlercreutz H, Katina K, Poutanen K, Aman P (2009) Physical, microscopic and chemical characterisation of industrial rye and wheat brans from the Nordic countries. Food Nutr Res 53(1), article 1912. https://doi. org/10.3402/fnr.v53i0.1912

Karlsson H (2007) Some aspects on strength properties in paper composed of different pulps. Licentiate thesis, Karlstad University Studies 2007:38, ISBN 978-91-7063-141-2

Kose R, Yamaguchi K, Okayama T (2016) Preparation of fine fiber sheets from recycled pulp fibers using aqueous counter collision. Cellulose 23(2):1393-1399. https://doi. org/10.1007/s10570-016-0874-5

López Alvarez JV, Aguilar Larrucea M, Arraiza Bermúdez P, León Chicote B (2009) Biodegradation of paper waste under controlled composting conditions. Waste Manag 9:1514-1519. https://doi.org/10.1016/j.wasman.2008.11. 025

Mitsch WJ, Bernal B, Nahlik AM, Mander U, Zhang L, Anderson CJ, Jørgensen SE, Brix H (2013) Wetlands, carbon, and climate change. Landsc Ecol 28(4):583-597. https://doi.org/10.1007/s10980-012-9758-8

Modzelewska I, Adamska K (2006) Application of cereal bran in production of paper products-initial investigations. Acta Sci Pol Silv 5(2):175-184

Modzelewska I, Cofta G, Jaszczur A (2006) Effect of the addition of pesticide on the biodegradation rate by microfungi of paper articles supplemented with cereal bran and their breaking strength. Folia For Pol B 41:69-79

Mostafa HM, Sourell H, Bockisch FJ (2010) Mechanical properties of some bioplastics under different soil types used as biodegradable drip tubes. Agric Eng Int CIGR J 12(1):12-21

Müller C, Kües U, Schöpper C, Kharazipour A (2007) Natural binders. In: Kües U (ed) Wood production, wood technology, and biotechnological impacts. Universitätsverlag Göttingen, Göttingen

Nambuthiri S, Fulcher A, Koeser AK, Geneve R, Niu G (2015) Moving toward sustainability with alternative containers for greenhouse and nursery crop production: a review and research update. HortTechnology 25(1):8-16

Nechita P, Dobrin E, Ciolacu F, Bobu E (2010) The biodegradability and mechanical strength of nutritive pots for vegetable planting based on lignocellulose composite materials. BioResources 5(2):1102-1113

Niero M, Hauschild MZ (2017) Closing the loop for packaging: finding a framework to operationalize circular economy strategies. Procedia CIRP 61:685-690. https://doi.org/10. 1016/j.procir.2016.11.209

Ochi S (2011) Durability of starch based biodegradable plastics reinforced with manila hemp fibers. Materials 4:457-468. https://doi.org/10.3390/ma4030457

Onipe OO, Jideani AO, Beswa D (2015) Composition and functionality of wheat bran and its application in some cereal food products. Int $\mathrm{J}$ Food Sci Technol 50:2509-2518. https://doi.org/10.1111/ijfs. 12935

Pagga U (1999) Compostable packaging materials-test methods and limit values for biodegradation. Appl Microbiol Biotechnol 51:125-133

PN-EN ISO 1924-2 (2009) Paper and board-determination of tensile properties, part 2: constant rate of elongation 
method (20 mm/min). Polish Committee for Standardization, Warsaw, Poland

PN-EN ISO 1974:2012P (2012) Determination of tearing resistance of paper-Elmendorf method. Polish Committee for Standardization, Warsaw, Poland

PN-EN 20535 (1996) Paper and board-determination of water absorptiveness-Cobb method. Polish Committee for Standardization, Warsaw, Poland

PN-EN ISO 2758 (2005) Paper-determination of bursting strength. Polish Committee for Standardization, Warsaw, Poland

PN-ISO 11004 (1995) Paper and board-determination of air permeance-low range. Polish Committee for Standardization, Warsaw, Poland

PN-ISO 1924-1 (1998) Paper and board—-determination of tensile properties-part 1: constant rate of loading method. International Organization for Standardization, Warsaw, Poland

Rahman A, Chattopadhyay G (2007) Soil factors behind inground decay of timber poles: testing and interpretation of results. IEEE Tran Power Del 22(3):1897-1903. https:// doi.org/10.1109/TPWRD.2007.893605

Retulainen E, Ebeling K (1993) Fibre-fibre bonding and ways of characterizing bond strength. Appita 46(4):282-288

Sandak A, Modzelewska I, Sandak J (2011) FT-NIR analysis of recycled paper with addition of cereal bran biodegraded with microfungi. J Near Infrared Spectrosc 19(5):369-379. https://doi.org/10.1255/jnirs.951

Sandak A, Jaszczur A, Sandak J, Modzelewska I (2015) Near infrared assessment of biodegradability and mechanical properties of paper made of cellulose sulphate bleached coniferous pulp with addition of cationic starch and resinous adhesive. Int Biodeterior Biodegrd 97:31-39. https:// doi.org/10.1016/j.ibiod.2014.09.019

Savitzky A, Golay MJE (1964) Smoothing and differentiation of data by simplified least squares procedures. Anal Chem 36(8):1627-1639

Schettini E, Santagata G, Malinconico M, Immirzi B, Mugnozza GS, Vox G (2013) Recycled wastes of tomato and hemp fibres for biodegradable pots: physico-chemical characterization and field performance. Resour Conserv Recycl 70:9-19. https://doi.org/10.1016/j.resconrec.2012.11.002

Schwanninger M, Rodrigues JC, Fackler K (2011) A review of band assignments in near infrared spectra of wood and wood components. J Near Infrared Spectrosc 19(5):287-308. https://doi.org/10.1255/jnirs.955

Scott G, Wiles DM (2001) Programmed-life plastics from polyolefins: a new look at sustainability. Biomacromol 2(3):615-622. https://doi.org/10.1021/bm010099h

Shogren RL (1999) Preparation and characterization of a biodegradable mulch: paper coated with polymerized vegetable oils. J Appl Polym Sci 73:2159-2167. https:// doi.org/10.1002/(SICI)1097-4628(19990912)73:11\% 3c2159:AID-APP12\%3e3.0.CO;2-Q

Song JH, Murphy RJ, Narayan R, Davies GBH (2009) Biodegradable and compostable alternatives to conventional plastics. Philos Trans R Soc Lond B Biol Sci 364(1526):2127-2139. https://doi.org/10.1098/rstb.2008. 0289

Sridach W, Hodgson KT, Nazhad MM (2007) Biodegradation and recycling potential of barrier coated paperboards. BioResources 2(2):179-192
Stahel WR (2016) The circular economy. Nature 531:435-438. https://doi.org/10.1038/531435a

T212 om-07 (2007) TAPPI One percent sodium hydroxide solubility of wood and pulp. Technical Association of the Pulp and Paper Industry, Peachtree Corners, USA

T804 om-12 (2006) TAPPI compression test of fiberboard shipping containers. Technical Association of the Pulp and Paper Industry, Peachtree Corners, USA

T207 cm-08 (2008) TAPPI water solubility of wood and pulp. Technical Association of the Pulp and Paper Industry, Peachtree Corners, USA

Tarrés Q, Oliver-Ortega H, Ferreira PJ, Pèlach MÀ, Mutjé P, Delgado-Aguilar M (2018) Towards a new generation of functional fiber-based packaging: cellulose nanofibers for improved barrier, mechanical and surface properties. Cellulose 25(1):683-695. https://doi.org/10.1007/s10570017-1572-7

Technical Association of the Pulp and Paper Industry, Peachtree Corners, USA

Tesfaye T, Sithole B, Ramjugernath D, Chunilall V (2017) Valorisation of chicken feathers: application in paper production. J Clean Prod 164:1324-1331. https://doi.org/ 10.1016/j.jclepro.2017.07.034

Treinyte J, Grazuleviciene V, Bridziuviene D, Svediene J (2014) Properties and behaviour of starch and rapeseed cake based composites in horticultural applications. Est $\mathrm{J}$ Ecol 63(1):15-27. https://doi.org/10.3176/eco.2014.1.02

Tumer AR, Karacaoglu E, Namli A, Keten A, Farasat S, Akcan R, Sert O, Odabasi AB (2013) Effects of different types of soil on decomposition: an experimental study. Leg Med 15(3):149-156. https://doi.org/10.1016/j.legalmed.2012. 11.003

Valdés A, Mellinas AC, Ramos M, Garrigós MC, Alfonso Jiménez A (2014) Natural additives and agricultural wastes in biopolymer formulations for food packaging. Front Chem 2, Article 6. https://doi.org/10.3389/fchem.2014. 00006

Villanueva A, Wenzel H (2007) Paper waste-recycling, incineration or landfilling? A review of existing life cycle assessments. Waste Manag 27(8):S29-S46. https://doi.org/ 10.1016/j.wasman.2007.02.019

Vroman I, Tighzert L (2009) Biodegradable polymers. Materials 2:307-344. https://doi.org/10.3390/ma2020307

Wistara N, Young RA (1999) Properties and treatments of pulps from recycled paper. Part I. Physical and chemical properties of pulps. Cellulose 6(4):291-324

Witkowska D, Bien M, Sobieszczański J (1989) The effect of trichoderma viride C-1 UV mutagenization on cellulases activity. Microbiologia 5(2):113-119

Yeomans PA (1954) The keyline plan. P.A. Yeomans 537 Elizabeth Street, Sydney

Yu Y (2001) The effect of fiber raw material on some toughness properties of paper. Doctoral thesis, Helsinki University of Technology, Helsinki, Finland

Publisher's Note Springer Nature remains neutral with regard to jurisdictional claims in published maps and institutional affiliations. 